vor sich, als bei Jodäthyl, Jodmethyl und ähnlichen Verbindungen. Die Untersuchung der organischen Körper in ihrem Verhalten gegen die Chlorverbindung der Radicale der fetten Säuren haben Rochleder und Hlasiwetz sich zur Aufgabe gemacht. Letzterer hat bereits aus Aesculetin ein Product dargestellt, das 3 Aeq. Acetyl an der Stelle von 3 Wasserstoff-Aeq. enthält, er hat 3 und 4 Aeq. Wasserstoff in der Gallussäure durch Acetyl substituirt. Es ist klar, dass die allgemein vorkommenden Bestandtheile der Pflanzen vor Allem in dieser Richtung der Untersuchung unterworfen werden mussten. Rochleder wird nächstens das Nähere über die Ergebnisse dieser Untersuchung mittheilen. (Sitzber. der Akad. der Wissensch. zu Wien. Bd. 24. - Chem. Centrbl. 1858. No. 5.)

$B$.

\title{
Bereitung von Ferrum reductum.
}

Nach M. Zängerle werden 12 Unzen Eisenvitriol in 18 Theilen Wasser gelöst, diese Lösung wird mit der von $4 \mathrm{Th}$. Oxalsäure in $8 \mathrm{Th}$. Wasser gefällt. Das ausgewaschene oxalsaure Eisenoxydul (ungefähr 5 Unzen) wird mit 6 Unzen feingepulvertem entwässertem Blutlaugensalze und 1 Unze 6 Drachmen reinem kohlensaurem Kali gemengt. Man glüht, bis keine Gasentwickelung mehr statt hat, und wäscht die Masse aus. (Buchn. n. Repert. - Chem. Centrbl. 1857. No. 20.)

\section{Gegenwart von Silber im Meerwasser.}

J. Field hat den Kupferbeschlag eines Schiffes, welches im stillen Ocean gekreuzt hatte, und welcher so zerfressen war, dass er sich leicht zwischen den Fingern zerbrechen liess, auf den Silbergehalt untersucht. In 5000 Gran des Kupferbeschlages fand er 2,01 Gran Silber. (Poggend. Annal. 1857. S. 349.)

E.

\section{Lichtstärke der Sonne.}

Aus einer Vergleichung des Sonnen-, Mond- und künstlichen Lichtes ergiebt sich, dass die Sonnenstrahlen eine Leuchtkraft haben gleich der von 14,000 Kerzen in einer Entfernung von 1 Fuss, oder von 3500 Quadratlinien Kerzen in einer Entfernung von 95 engl. Meilen. Hieraus folgt, dass die Lichtmasse, welche der Sonnenscheibe ent- 